\title{
Chapter 10: 3D cell culture models of epithelial tissues
}

\section{Kai Zhang and Aki Manninen}

Biocenter Oulu, Oulu Center for Cell-Matrix Research, Faculty of Biochemistry and Molecular Medicine, University of Oulu, Oulu, Finland, aki.manninen@oulu.fi

\begin{abstract}
:
Cells in tissues in vivo face a very different microenvironment than typical cultured cells plated on a plastic dish. Already several decades ago, cell biologists observed that cell lines show dramatically different morphology and growth characteristics when embedded into 3-dimensional (3D) substrates or standard tissue culture plates (Barcellos-Hoff et al. 1989, Montesano et al. 1991, Simian and Bissell 2017). Despite its imminent benefit for cell biological studies, suspicion and prejudice towards more complicated sample preparation requirements limited the popularity of 3D culture techniques until recently, when it was shown that soft 3D gels made of basement membrane extracts (BME) allow prolonged culture of many types of primary epithelial cells (Clevers 2016, Sato et al. 2009). These observations have brought 3D organoid culture systems into the mainstream. Here we describe two protocols for culturing epithelial cells in 3D substrates, the "blob culture" setup where cells are fully embedded into BME gel and the "overlay setup" where cells are seeded on top of BME gel and then overlaid with a thin layer of BME (Bryant et al. 2010, Debnath and Brugge 2005).
\end{abstract}

Key words: MDCK, 3D culture, organoid 


\section{Introduction}

Most of the early 3D culture work was based on Madin-Darby canine kidney (MDCK) and various mammary epithelial cell lines such as MCF10A. Here we describe a protocol developed for 3D Matrigel ${ }^{\circledR}$ culture of MDCK cells, but the protocol is also applicable to most other epithelial cell lines (Manninen 2015). Obviously, the mixture of growth and other factors that need to be added to the culture medium must be optimized separately for different cell lines and are of particular importance when culturing primary cell organoids. The selection of the appropriate method from the two variations of the protocol depends on the analysis to be made. The blob setup allows growth of higher number of cells and they can be mounted for high resolution imaging using confocal microscopy, but are less accessible for high-resolution live cell imaging (Myllymäki et al. 2011). The overlay setup is more suitable for live-cell imaging studies and readily certain manipulations, such as viral transduction of organoid cultures, during culture (Zhang et al. 2017).

\section{Materials}

Prepare all solutions intended for cell culture using sterile ultrapure water and work aseptically in a laminar flow cabinet. All materials should be cell culture tested and of high purity.

\subsection{MDCK cell culture}

1. 3D Complete culture medium: MEM-Glutamax (41090-093, Life Technologies) supplied with $10 \%$ fetal bovine serum (FBS, Life Technologies) and 1\% penicillin/streptomycin (15140122, Gibco).

2. 2D Complete culture medium: as above, but with 5\% FBS

3. Trypsin-EDTA (25200056, Gibco)

4. Matrigel ${ }^{\circledR}$ matrix (354230, BD Biosciences), thaw on ice, mix well and aliquot into microtubes and store at $-80^{\circ} \mathrm{C}$.

5. $35 \mathrm{~mm} \varnothing$ glass-bottom $\mu$-Dish (81158, IBIDI), cool it on ice before use.

\subsection{Immunofluorescence (IF)}

1. Fixation buffer: $3-4 \%$ (para)formaldehyde (PFA) in PBS (Note! $0.1 \%$ 
glutaraldehyde may need to be added into PFA-solution if your Matrigel ${ }^{\circledR}$ blobs dissolve during PFA-fixation).

2. Fixative quenching buffer: $100 \mathrm{mM}$ glycine in PBS.

3. Permeabilization buffer: $0.2 \% \mathrm{TX}-100$ in PBS.

4. IF Buffer (130 mM NaCl; $7 \mathrm{mM} \mathrm{Na}_{2} \mathrm{HPO}_{4} ; 3.5 \mathrm{mM} \mathrm{NaH}_{2} \mathrm{PO}_{4} ; 7.7 \mathrm{mM} \mathrm{NaN}_{3} ; 0.1 \%$ BSA; $0.2 \%$ Triton X-100; $0.05 \%$ Tween-20)

5. Nuclear dye: $1 \mathrm{mg} / \mathrm{ml}$ of 4',6-diamidino-2-phenylindole (DAPI, D9542, Sigma) in PBS.

6. Mounting medium: ImmuMount (9990402, Thermo Scientific).

7. A confocal microscope with appropriate image analysis software, such as Zeiss LSM 780 confocal microscope, 40x Plan-Apochromat objective $(N . A=1.4)$ and the ZEN 2011 software.

\subsection{Live cell imaging}

1. A fluorescent protein-based marker to label cells such as mRed-fused to histone $2 B$ to stain cell nuclei (pHIV- H2B-mRed lentivirus vector (Welm et al. 2008; Addgene \#18982) was used in this example).

(OPTIONAL STEP: Fluorescence-activated cell sorting (FACS) setup such as Becton Dickinson FACSAria ${ }^{\mathrm{TM}}$ III Cell Sorter may be used in order to enrich for positively transduced cells.)

2. A sensitive spinning disc confocal microscopy setup with environmental control and suitable image analysis software such as Zeiss Cell Observer with a spinning disc unit (Yokogawa CSU-X1) and Hamamatsu EMCCD camera equipped with humidified, environmental control incubator $\left(37^{\circ} \mathrm{C}, 5 \% \mathrm{CO}_{2}\right)$ and Zen 2012 (Blue edition) software.

\section{Methods}

\subsection{D overlay culture of MDCK cells}

1. Split nearly confluent MDCK cells one day before 1:5. This helps to avoid cell clumping that is detrimental for proper growth of MDCK cysts in 3D gels.

2. Thaw Matrigel ${ }^{\circledR}$ on ice (Allow 1-2 hrs for small aliquots $(<1 \mathrm{ml})$ and overnight for larger aliquots (1-10ml). Note: Always keep Matrigel® on ice; it will solidify at room temperature. 
3. Add 150-200 $\mu 1$ Matrigel® onto a 35mm high $\mu$-Dish. Spread Matrigel® evenly with a 200ul tip to reduce possible meniscus forming at the edges of the glass bottom dish. Take care not to generate air bubbles. Place the dish at $+4^{\circ} \mathrm{C}$ for $5 \mathrm{~min}$.

4. Transfer the dish into $+37^{\circ} \mathrm{C}, \mathrm{CO}_{2}$ incubator and allow 20 minutes for the Matrigel ${ }^{\circledR}$ to solidify.

5. Wash cells ( 40-60\% confluent) with PBS, add $2 \mathrm{ml}$ of Trypsin-EDTA and incubate for 10 minutes or until cell detach at $+37^{\circ} \mathrm{C}$. Resuspend trypsinized cells into $8 \mathrm{ml}$ of 2D complete culture medium.

6. Count cells and aliquot 60,000 cells into a fresh $15 \mathrm{ml}$ conical tube; fill to $10 \mathrm{ml}$ with 2D complete culture medium.

7. Tube A (cell suspension): Pellet cells at 150xg for 3 minutes. Resuspend cell pellet into $5 \mathrm{ml}$ of 3D culture medium. (label this tube "A"). This will generate 1200 cells/100 $\mu 1,750 \mu \mathrm{l}$ or 9000 cells will be seeded per dish.

8. Tube B (diluted Matrigel®): Prepare 3D 750 $\mu 1$ per sample of 3D culture medium containing 4\% Matrigel ${ }^{\circledR}$ (label this tube "B"). NOTE! Use ice-cold medium to prevent premature gelation of Matrigel@.

9. Mix $750 \mu 1$ of Tube A and $750 \mu 1$ of Tube B and plate the mixture onto Matrigel®coated $\mu$-Dish prepared in step 3. Gently transfer the dish into the $\mathrm{CO}_{2}$-incubator.

10. Exchange media every two days with fresh culture medium containing $2 \%$ Matrigel ${ }^{\circledR}$ and culture for 6 days. If the culture is continued for prolonged times you can omit the Matrigel ${ }^{\circledR}$ from the fresh medium after $6^{\text {th }}$ day.

\subsection{Time lapse imaging of MDCK cells in 3D overlay cultures}

1. MDCK cells stably expressing H2B-mRed were set up for $3 \mathrm{D}$ culture in $35 \mathrm{~mm}$ glass-bottom $\mu$-Dish (81158, Ibidi) as described in 3.1. and cultured for 72 hours in a normal humidified $\mathrm{CO}_{2}$-incubator at $+37^{\circ} \mathrm{C}$.

2. Live imaging was initiated by placing the $\mu$-Dish into Zeiss spinning disk confocal microscope equipped with a spinning disc unit (Yokogawa CSU-X1), Hamamatsu EMCCD camera, EC Plan NeoFluar 40x/0.75 DIC (dry/air) objective and humidified, environmental control incubator $\left(37^{\circ} \mathrm{C}, 5 \% \mathrm{CO}_{2}\right)$.

3. Multipoint imaging was performed by capturing image stacks of complete cysts every $30 \mathrm{~min}$ for a duration of 27 hours using Zen 2012 software (Blue edition; Figure 1). 


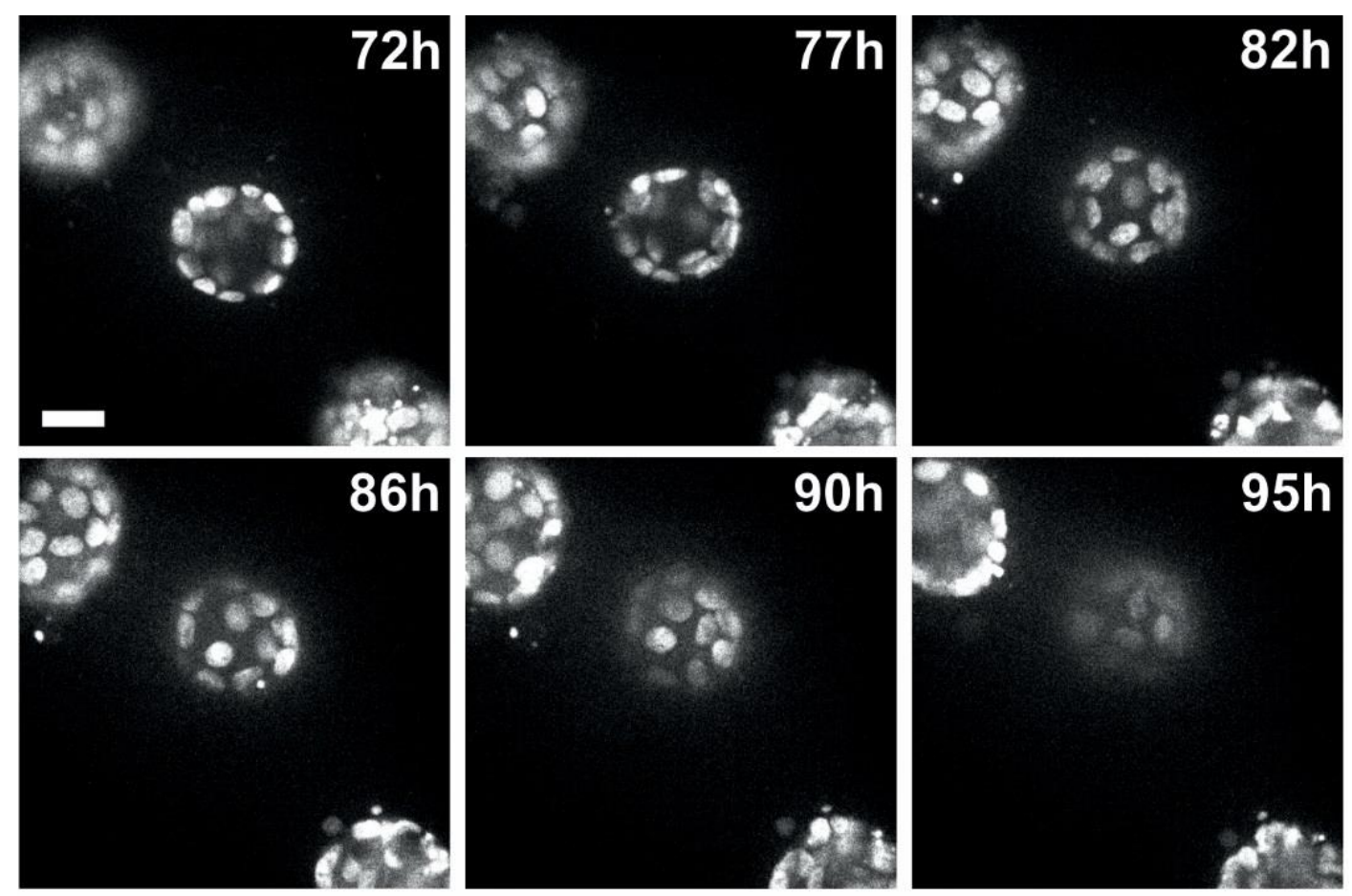

Figure 1. Timelapse imaging of $3 D$ overlay culture of MDCK cells. $H 2 B-$ $m$ Red expressing MDCK cells were first cultured in $3 D$ overlay setup for 72 hours and then placed into an incubation chamber at a spinning disk confocal microscope and imaged at 30 minutes intervals as described in 3.2. Selected time points are shown. The scale bar is $20 \mu \mathrm{m}$.

\subsection{D blob culture of MDCK cells}

Important! Do pipetting gently but swiftly, try to keep all the Matrigel ${ }^{\circledR}$ mixtures ice-cool to prevent (chilled metal block in the laminar) premature gel-formation.

1. Split nearly confluent MDCK cells one day before 1:5. This helps to avoid cell clumping that is detrimental for proper growth of MDCK cysts in $3 \mathrm{D}$ gels.

2. Thaw sufficient amount of Matrigel ${ }^{\circledR}$ on ice (for example, $\sim 150 \mu 1$ per sample with 3 replicates).

3. Chill sterile eppendorf tubes (one per each sample) on ice (preferably a metal block that can be easily transferred into laminar hood when seeding the cysts).

4. Once thawn, pipette $150 \mu$ l of Matrigel ${ }^{\circledR}$ into each of the chilled tubes - keep cold if you have problems with Matrigel ${ }^{\circledR}$ gelling too fast, use pre-chilled tips in all steps that involve Matrigel ${ }^{\circledR}$.

5. Wash cells ( $40-60 \%$ confluent) with PBS, add $2 \mathrm{ml}$ of Trypsin-EDTA and incubate for 10 minutes or until cell detach at $+37^{\circ} \mathrm{C}$. Resuspend trypsinized cells into $8 \mathrm{ml}$ of 2D complete culture medium. 
6. Count cells and aliquot 1 million cells into a fresh $15 \mathrm{ml}$ conical tube; fill to $10 \mathrm{ml}$ with 2D complete culture medium.

7. Pellet cells at $150 x$ g for 3 minutes. Resuspend cell pellet into $400 \mu 1$ of 3D culture medium $\left(1 \times 10^{6}\right.$ cells $\left./ \mathrm{ml}\right)$.

8. Resuspend cells and transfer $10 \mu \mathrm{l}$ of cell suspension (25,000 cells) into Matrigel ${ }^{\circledR}$ tube, mix swiftly by pipetting but avoid air bubbles.

9. Using a $200 \mu 1$ pipette, gently mix twice and dispense three $\sim 50 \mu 1$ blobs each into the center of a well in 24-well plate - avoid contact with the sides of the well and be careful not to make air bubbles. If air bubbles form you can try to remove them with a pipette before the gel solidifies

10. When you have pipetted all of the blobs for all of the samples transfer the plate into $+37^{\circ} \mathrm{C} \mathrm{CO}_{2}$-incubator for $30 \mathrm{~min}$ to allow solidification then add $1.5 \mathrm{ml}$ of $3 \mathrm{D}$ culture medium per well.

11. Grow cells for 4-10 days and change the growth medium every 2-3 days. Fully polarized MDCK cysts form in 4-7 days.

\subsection{Immunofluorescence and preparation of blob cultures for confocal imaging}

1. For immunofluorescence analysis, the blobs are fixed in the wells by pipetting $1 \mathrm{ml}$ of PFA ( $+0.1 \%$ glutaraldehyde, see 2.2.) to the side of the wells and incubating for 20 minutes at room temperature.

2. If necessary, cells are permeabilized by incubating with permeabilization buffer for 30 minutes followed by incubation for 30 minutes in quenching buffer, both at room temperature.

3. Nonspecific binding sites are blocked by a 1-hour incubation with in blocking buffer at room temperature.

4. Primary antibodies: Incubate with primary antibodies in IF Buffer (use 2- to 4-fold concentrations compared with normal immunofluorescence in 2D) overnight at $+4^{\circ} \mathrm{C}$, carefully rinse once with 1,5 $\mathrm{ml}$ of IF buffer and perform three 20 minutes washes with IF buffer at room temperature with gentle rocking.

5. Secondary antibodies: Incubate with 1:400 dilution of fluorophore-conjugated secondary antibody in IF buffer for 4 hours at room temperature or overnight at $+4^{\circ} \mathrm{C}$. In nuclear and/or actin cytoskeletal staining is needed, add DAPI (Sigma) and fluorophore-conjugated phalloidin, respectively, at this step together with 
secondary antibodies. Rinse once with PBS and wash 3 times 20 minutes each as above. Samples are mounted by pipetting them onto a slide with tape spacers with an end-cut $200 \mu \mathrm{l}$ tip, overlaid with $100 \mu 1$ of ImmuMount (Thermo Scientific) and a coverslip (Figure 2).

6. Confocal laser scanning microscopy (LSM) images are best acquired by using confocal microscopy such as Zeiss LSM 780 confocal microscope with a 40x PlanApochromat objective $($ N.A $=1.4)$. Roughly 30 confocal stacks were acquired with $400 \mathrm{~nm}$ increments from the basal region of cysts containing matrix adhesions using the ZEN 2011 software.

\section{Acknowledgements}

Riitta Jokela is acknowledged for overall expert technical assistance, Jaana Träskelin for expert technical assistance at Biocenter Oulu Virus Core Laboratory and Veli-Pekka Ronkainen for expert assistance in microscopy at Biocenter Oulu Tissue Imaging Center. This work was funded by Academy of Finland (251314, 135560, 263770, and 140974 /AM). 


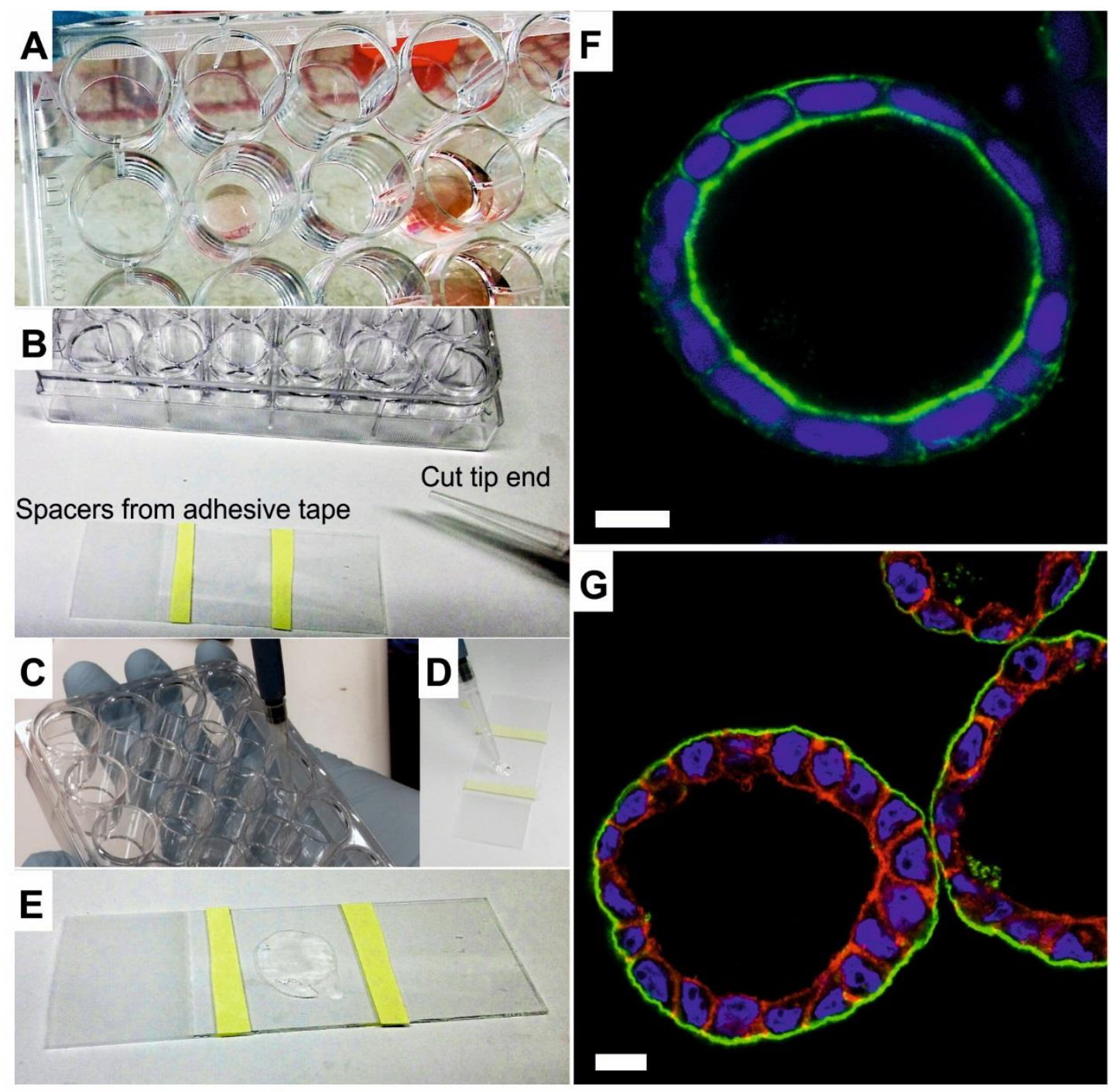

Figure 2. Mounting and confocal microscopy of blob cultures. A) Blobs are fixed and stained in 24-well plate wells as described in 3.4. B-D) Pieces of adhesive tape are used as spacers on slides and tip end is cut with scissors to allow easy pipetting of Matrigel ${ }^{\circledR}$ onto the slide. E) Matrigel is overlaid mounting medium and gently flattened by placing a coverslip onto spacers. F) MDCK cysts were grown for 6 days as described in 3.3. and stained for filamentous actin using Alexa Fluor 488®-phalloidin (green; A12379, Thermo Fischer Scientific). Nuclei were stained with DAPI (blue). G) Many types of epithelial cells form hollow cysts in $3 D$ Matrigel ${ }^{\circledR}$ cultures. RWPE-1 human prostate epithelial cells were grown for 6 days as described above (except for using Keratinocyte-SFM;Cat.\# 17005042, Thermo Fischer Scientific). Cells were stained for a6-integrin that marks basal surface of epithelial cells (green; GoH3/Abcam \#ab105669), filamentous actin (red; TRITC-phalloidin, P1951, Sigma) and nuclei (blue; DAPI).Scale bar in F and G is $10 \mu \mathrm{m}$. 


\section{References}

Barcellos-Hoff MH, Aggeler J, Ram TG, Bissell MJ (1989) Functional differentiation and alveolar morphogenesis of primary mammary cultures on reconstituted basement membrane. Development 105:223-235

Bryant DM, Datta A, Rodriguez-Fraticelli AE, Peranen J, Martin-Belmonte F, Mostov KE (2010) A molecular network for de novo generation of the apical surface and lumen. Nat Cell Biol 12:1035-1045

Clevers H (2016) Modeling Development and Disease with Organoids. Cell 165:15861597

Debnath J, Brugge JS (2005) Modelling glandular epithelial cancers in threedimensional cultures. Nat Rev Cancer 5:675-688

Manninen A (2015) Epithelial polarity - Generating and integrating signals from the ECM with integrins. Exp Cell Res 334:337-349

Montesano R, Schaller G, Orci L (1991) Induction of epithelial tubular morphogenesis in vitro by fibroblast-derived soluble factors. Cell 66:697-711

Myllymäki SM, Teräväinen TP, Manninen A (2011) Two distinct integrin-mediated mechanisms contribute to apical lumen formation in epithelial cells. PLoS One 6:e19453

Sato T, Vries RG, Snippert HJ, van de Wetering M, Barker N, Stange DE, van Es JH, Abo A, Kujala P, Peters PJ, Clevers H (2009) Single Lgr5 stem cells build crypt-villus structures in vitro without a mesenchymal niche. Nature 459:262-265

Simian M, Bissell MJ (2017) Organoids: A historical perspective of thinking in three dimensions. J Cell Biol 216:31-40 
Welm BE, Dijkgraaf GJ, Bledau AS, Welm AL, Werb Z (2008) Lentiviral transduction of mammary stem cells for analysis of gene function during development and cancer. Cell Stem Cell 2:90-102

Zhang K, Myllymaki SM, Gao P, Devarajan R, Kytola V, Nykter M, Wei GH, Manninen A (2017) Oncogenic K-Ras upregulates ITGA6 expression via FOSL1 to induce anoikis resistance and synergizes with alphaV-Class integrins to promote EMT. Oncogene advance online publication 12 June, doi: 10.1038/onc.2017.177 